\title{
PREVALENCE OF HIV-TB CO-INFECTION IN GAUTAM BUDH NAGAR OF WESTERN UTTAR PRADESH
}

\author{
Hari Mohan Kansal'1, Dheerendra Kuber², Saurabh Srivastava³, Neeta Bhardwaj ${ }^{4}$
}

${ }^{1}$ Associate Professor, Department of Pulmonary Medicine, School of Medical Sciences and Research, Sharda University, Greater Noida. ${ }_{2}^{2}$ Assistant Professor, Department of Medicine, School of Medical Sciences and Research, Sharda University, Greater Noida.

3 Professor, Department of Medicine, School of Medical Sciences and Research, Sharda University, Greater Noida.

${ }^{4}$ Senior Councillor, ICTC Noida.

\section{ABSTRACT}

\section{OBJECTIVE}

The burden of Human Immunodeficiency Virus (HIV) as well as Tuberculosis (TB) is very high in Sub-Saharan Africa and South East Asian region including India. HIV-TB co-infection pose to be major health problem in this region as this has far more detrimental effects than HIV or TB alone. The present study was planned to assess the prevalence of co infection in the region of western Uttar Pradesh.

\section{MATERIAL AND METHODS}

The patients presenting to a tertiary care centre as well as an Integrated Counselling and Test Centre (ICTC) of Western Uttar Pradesh over a period of one year were recruited for the study.

\section{RESULTS}

The overall co-infection rate was $2.48 \%$. Most common mode of transmission was heterosexual and maximum patients were driver by their occupation.

\section{KEYWORDS}

HIV-TB Co-Infection, HIV, Tuberculosis, ICTC.

HOW TO CITE THIS ARTICLE: Kansal HM, Kuber D, Srivastava S, et al. Prevalence of HIV-TB co-infection in Gautam Budh Nagar of Western Uttar Pradesh. J. Evolution. Med. Dent. Sci. 2016;5(11):446-448, DOI: 10.14260/jemds/2016/102

\section{INTRODUCTION}

The Acquired Immune Deficiency Syndrome (AIDS) pandemic has focused primarily on Sub-Saharan Africa and South East Asian region. In addition, these countries are facing tuberculosis as a major health problem, a disease that kills approximately two million people each year. Tuberculosis (TB) epidemiology is affected by the increasing rate of Human Immunodeficiency Virus (HIV) infection. HIV is an important risk factor in promotion and progression to active TB.[1] The immune-competent persons have a $5 \%$ to $10 \%$ life-time risk of tuberculosis, while there is a $5 \%$ to $15 \%$ annual risk of developing active tuberculosis in HIV positive individuals.[2] India ranks very high in terms of incident TB cases. The burden of tuberculosis and HIV/AIDS pose unprecedented challenges on the public health system in India. Globally, India has the highest number of tuberculosis cases and second highest number of HIV-infected people after South Africa. The HIV pandemic presents a massive challenge to the control of TB at all levels. TB is also one of the most common causes of morbidity and one of the leading causes of mortality in people living with HIV/AIDS.[3]

In India, about half of 5.1 million people infected with HIV are co-infected with M. tuberculosis, approximately 0.2

Financial or Other, Competing Interest: None.

Submission 22-12-2015, Peer Review 14-01-2016,

Acceptance 25-01-2016, Published 05-02-2016.

Corresponding Author:

Dr. Hari Mohan Kansal,

Associate Professor, Department of Pulmonary Medicine,

School of Medical Sciences and Research,

Sharda University, 32-34, Knowledge Park III,

Greater Noida, Uttar Pradesh (India).

E-mail: kansalhm@gmail.com

DOI: 10.14260/jemds/2016/102 million of these co-infected persons, each year will develop active tuberculosis in association with HIV infection. ${ }^{[4]}$ Reports from other parts of country also have shown higher incidence of HIV infection in person with tuberculosis. ${ }^{[5-7]}$ The commonest AIDS defining illness in Western Countries is Pneumocystis pneumonia.[8] while TB is the most common opportunistic infection in developing countries. [9] Co-infection with HIV-TB has far more detrimental effects than HIV or TB alone.

In the present study, authors had studied the presence of HIV-TB co-infection and the demographic profile of patients presenting to a tertiary care centre as well as an Integrated Counselling and Test Centre (ICTC) of Western Uttar Pradesh.

\section{MATERIAL AND METHODS}

In the present study, all the patients presenting to a tertiary care centre as well as an Integrated Counselling and Test Centre (ICTC) of Western Uttar Pradesh over a period of one year were recruited for the study.

The patients who were referred from Revised National Tuberculosis Control Programme (RNTCP) Centre to ICTC with a positive history of tuberculosis as well as the patients having any form of tuberculosis admitted to the tertiary care centre were enrolled for the study. The diagnosis of tuberculosis at tertiary care centre was based on detailed clinical history, general and systemic examination, chest radiograph and sputum smear for Acid Fast Bacilli (AFB). In case of extra-pulmonary (EPTB), relevant samples were obtained for pathological, biochemical and cytological examinations.

All the patients included in study were screened for HIV antibodies. The meaning and implication of this test were explained and a written consent was obtained prior to HIV testing. Serum samples were collected and assayed for 
antibodies against HIV using HIV comb immunoassay kits, viz. comb AIDS-RS, SD Bioline, either at the ICTC or the laboratory of tertiary care centre. The presence of HIV-TB co-infection was determined among the examined tubercular patients.

\section{RESULTS}

Nine hundred and sixty nine patients of tuberculosis from a tertiary care centre and ICTC of Western Uttar Pradesh were screened for the co-infection of HIV and 24 of them were found to be co-infected. Out of 143 patients from the tertiary care centre, 7 patients were found to be suffering from co-infection and 17 patients were found to be co-infected out of 826 patients from ICTC. The overall co-infection rate was $2.48 \%$, however highest percentage of co-infection (3.72\%) was found in the age group of 35 to 50 years. Male-to-female ratio was approximately 2:1. (Table 1 ).

Most common mode of transmission was heterosexual in $45.8 \%$ patients followed by blood products and IV drug use in $37.5 \%$ patients. (Table 2 ).

Fifty percent of the patients with co-infection were driver by their occupation followed by housewives in $20.8 \%$ patients, the occupations of other patients in small numbers were labourers and farmers. (Table 3).

\begin{tabular}{|c|c|c|c|c|c|c|c|}
\hline \multirow[t]{3}{*}{ Age (Yrs) } & \multicolumn{6}{|c|}{$\begin{array}{l}\text { Number of } \\
\text { Patients }\end{array}$} & \multirow[t]{3}{*}{ Percentage } \\
\hline & \multicolumn{2}{|c|}{ Tertiary Centre } & \multicolumn{2}{|c|}{ ICTC } & \multicolumn{2}{|c|}{ Total } & \\
\hline & TB & HIV & TB & HIV & TB & HIV & \\
\hline$<15$ & 0 & 0 & 0 & 0 & 0 & 0 & 0 \\
\hline $15-34$ & 63 & 2 & 263 & 5 & 326 & 7 & $2.14 \%$ \\
\hline $35-50$ & 43 & 5 & 386 & 11 & 429 & 16 & $3.72 \%$ \\
\hline$>50$ & 37 & 0 & 177 & 1 & 214 & 1 & $0.46 \%$ \\
\hline Total & 143 & 7 & 826 & 17 & 969 & 24 & $2.48 \%$ \\
\hline \multicolumn{8}{|c|}{ Sex } \\
\hline Male & 92 & 5 & 508 & 12 & 600 & 17 & $2.83 \%$ \\
\hline Female & 51 & 2 & 318 & 5 & 369 & 7 & $1.89 \%$ \\
\hline
\end{tabular}

\begin{tabular}{|c|c|c|c|}
\hline $\begin{array}{c}\text { Modes of } \\
\text { Transmission }\end{array}$ & $\begin{array}{c}\text { Tertiary } \\
\text { Centre }\end{array}$ & ICTC & Total \\
\hline Heterosexual & 2 & 9 & $11(45.8 \%)$ \\
\hline $\begin{array}{c}\text { Blood products/IV } \\
\text { drugs }\end{array}$ & 2 & 7 & $9(37.5 \%)$ \\
\hline Homosexual & 0 & 1 & $1(4.1 \%)$ \\
\hline Unidentified & 3 & 0 & $3(12.5 \%)$ \\
\hline Table 2: Modes of transmission of HIV in the patients \\
\hline
\end{tabular}

\begin{tabular}{|c|c|c|c|}
\hline Occupation & $\begin{array}{c}\text { Tertiary } \\
\text { Centre }\end{array}$ & ICTC & Total \\
\hline Driver & 3 & 9 & $12(50 \%)$ \\
\hline Labourer & 1 & 2 & $3(12.5 \%)$ \\
\hline Farmer & 1 & 1 & $2(8.3 \%)$ \\
\hline Housewife & 2 & 3 & $5(20.8 \%)$ \\
\hline Others & 0 & 2 & $2(8.3 \%)$ \\
\hline \multicolumn{2}{|c|}{ Table 3: Occupation of patients affected with HIV } \\
\hline
\end{tabular}

\section{DISCUSSION}

The tuberculosis situation in the country is threatened and complicated by the emergence and spread of HIV and drugresistant tuberculosis. Tuberculosis is the earliest and the most common opportunistic disease that develops amongst persons infected with HIV. An HIV positive person co-infected with Mycobacterium tuberculosis had about 50-60\% life-time risk of developing tuberculosis. ${ }^{[3]}$ The TB epidemic in India is pre-dominantly driven by the non-HIV positive TB cases. It is further estimated that approximately $5 \%$ of all TB patients are infected with HIV.[10] The survey in TB patients assessing the co-infection with HIV was carried out in around 15 districts up to 2007. The 2007 survey represents the detailed evaluation of HIV epidemiology among TB patients in India. The prevalence of HIV-TB co-infection was found to be between $1 \%$ and $13.8 \%$ across the 15 surveyed districts and varied substantially across the geographic regions.[11]
In the present study which was conducted in a tertiary care centre and an ICTC centre of Western Uttar Pradesh, the prevalence of HIV-TB co-infection was found to be $2.5 \%$. A similar type of study done from Uttarakhand had found an increasing prevalence of the co-infection to up-to $4.19 \%$ in 2005. The other studies done in the various western and southern part of India have shown a higher and increasing sero-prevalence of HIV-TB co-infection. ${ }^{[5,12,13]}$

The most common age group with the co-infection was 35-50 yrs. followed by in the age group of 15-34 yrs. with a male preponderance. The various other studies done in India and abroad had found the highest prevalence in the age group of 20-40 yrs. also with a male preponderance signifying that in the present study older age group was having a higher incidence of co-infection.[14-17]

Most common route of HIV transmission found in our study was heterosexual route followed by blood transfusion and IV drug use. Other Indian studies have shown similar observations.

The most common occupation of the patient in the present study was drivers. The highest sero-prevalence of HIV is also shown to be in drivers, probably the same is being reflected in the co-infection. Other studies have found manual labourer as the most common occupation followed by drivers, which is not seen in our study.[18]

The most common form of tuberculosis diagnosed in these patients was sputum positive pulmonary tuberculosis; the lesions found on chest radiograph were not typically involving the upper lobe but were disseminated in whole of the lung fields. These findings are in contrast to the study done from the neighbouring state Uttarakhand where extrapulmonary tuberculosis was most common from.[18] This finding can be explained by the advanced immunosuppression seen in HIV patients in whom upper lobe predilection and 
extra-pulmonary form becomes less common due to decreased immunity.

In response to the dual epidemic of HIV and TB, the World Health Organization (WHO) has recommended guidelines for HIV and TB prevention, care and treatment services. These include interventions that reduce the morbidity and mortality from TB in people living with HIV/AIDS. Further the interdepartmental referral between ICTC centre and a RNTCP centre has been established with the efforts of National AIDS Control Organization (NACO), in which the tuberculosis patients are being referred to ICTC centre by RNTCP and the HIV patients are been referred to RNTCP for investigation to rule out tuberculosis.

\section{CONCLUSION}

HIV-TB co-infection is to be considered in the patients presenting with either tuberculosis or HIV, even though the prevalence is not very high. The main mode of transmission was heterosexual and the common population affected was drivers. As incidence of HIV is increasing in the developing countries like India, the burden of co-infection is also increasing, as tuberculosis is already prevalent in these regions and immuno-compromised state created by HIV makes the person susceptible to tuberculosis.

\section{REFERENCES}

1. TB/HIV, A Clinical Manual, WHO 2004 accessed from http://whqlibdoc.who.int/publications/2004/9241546 344.pdf on 13/02/2014.

2. Soumya Swaminathan, G Narendran. HIV and tuberculosis in India. J Biosci 2008;33(4):527-537.

3. Pradeep Seth. The situation of HIV/M. tuberculosis coinfection in India. The Open Infectious Diseases Journal 2011; 5, (Suppl 1-M5): 51-59.

4. Khatri GR, Frieden TR. Controlling tuberculosis in India. N Engl J Med 2002;347:1420-5.

5. Mohanty KC, Basheer PMM. Changing trend of HIV infection and tuberculosis in a Bombay area since 1988. Indian J Tuberc 1995;42:117.

6. Mohanty KC, Sundrani RM, Nair S. HIV infection in patients with respiratory disease. Indian J Tuberc 1993;40:5-12.
7. Mohanty KC, Nair, Sahasrabudhe T. Changing trend of HIV infection in patients with respiratory diseases in Bombay since 1988. Indian J Tuberc 1994;41:147-149.

8. Mocroft A, Youle M, Morcinek J, et al. Survival after diagnosis of AIDS: a prospective observational study of 2625 patients. Royal Free/Chelsea and Westminster Hospitals Collaborative Group. BMJ; 314:409-13.

9. Sharma SK, Kadhiravan T, Banga A, et al. Spectrum of clinical disease in a cohort of 135 hospitalised HIVinfected patients from North India. BMC Infect Dis 2004;4:52.

10. Robert Steinbrook. Tuberculosis and HIV in India. N Engl J Med 2007;356:1198-1199.

11. The HIV-TB co-infection. National AIDS Control Organization and Central TB Division. Ministry of health and Family Welfare, Government of India 2008 (Available at http://www.nacoonline.org).

12. Jain SK, Aggarwal JK, Rajpal S, et al. Prevalence of HIV infection among tuberculosis patients in Delhi-A sentinel surveillance study. Indian J Tuberc 2000;47:21.

13. Tripathi S, Joshi DR, Mehendale SM, et al. Sentinel surveillance for HIV infection in tuberculosis patients in India. Indian J Tuberc 2002;49:17-20.

14. Deivanayagam CN, Rajasekaran S, Senthilnthan V, et al. Clinico-radiological spectrum of tuberculosis aiming HIV seropositives: a Tambram study. Indian J Tuberc 2001;48:123-27.

15. Samuel NM, Alarnelu C, Jagannath K, et al. Detection of HIV infection in pulmonary tuberculosis patients. J Indian Med Assc 1996;94:331-33.

16. Pitchenick AE, Fertel D, Block AB. Mycobacterial disease: epidemiology, diagnosis and prevention. Clin Chest Med 1988;9:425-41.

17. Rajasekaran S, Uma A, Kamakshi S, et al. Trend of HIV infection in patients with tuberculosis in rural South India. Indian J Tuberc 2000;47:223-26.

18. Pratima Gupta, Jagdish Rawat, Girish Sindhwani, Ramjee Prasad, Manju Talekar. HIV sero-prevalence and tuberculosis in Uttaranchal. Indian J Tuberc 2006;53:96-100. 